\title{
Narrativas infantis: um estudo de caso em uma instituição infantil
}

\author{
Tizuko Morchida Kishimoto \\ Universidade de São Paulo \\ Maria Letícia Ribeiro dos Santos \\ Dorli Ribeiro Basílio \\ Escola Municipal de Educação Infantil Benedicto Castrucci
}

Correspondência:

Tizuko Morchida Kishimoto

Faculdade de Educação da USP

Av. da Universidade, 308/Depto EDM

05508-040 - São Paulo - SP

e-mail: tmkishim@usp.br

\section{Resumo}

Enfrentando a pedagogia tradicional adultocêntrica, uma professora de Educação Infantil conduz projetos com a participação das crianças em uma sala com áreas diversificadas para brincandeiras livres. Ao utilizar a abordagem de projetos integrada aos pressupostos do High/Scope, a professora valoriza os saberes e as narrativas das crianças durante a construção de uma bruxa com caixa de papelão. 0 caso focaliza narrativas contendo expressões verbais de natureza binária, típicas do processo de categorização da criança, pesquisadas por Bruner e similares às do pensamento selvagem analisado por Lévi-Strauss. 0 contexto da pesquisa: espaço físico da sala de atividade, reformulado em 2003, conforme pressupostos do modelo curricular High/Scope e enriquecido com a Abordagem de Projetos. A pesquisa, qualitativa, configura um estudo de caso instrumental, colaborativo, em que uma professora de uma escola municipal de Educação Infantil da cidade de São Paulo desenvolve, com crianças de quatro anos, a prática de contar história em um ambiente que estimula a cooperação, o lúdico e as narrativas. Os resultados indicam que, segundo concepções brunerianas, as narrativas infantis binárias, como bruxa boa e má, morar perto e longe, caixa grande e pequena, evidenciam estruturas típicas do pensamento infantil, que auxiliam no processo de categorização de situações do cotidiano. Práticas de contar histórias, de ouvir a criança e de criar espaço para a recriação de narrativas são coerentes com pedagogias que respeitam as formas de representação do mundo da criança, como a abordagem de projetos.

\section{Palavras-chave}

Narrativas infantis - Abordagem de projetos - Pensamento binário Andaime. 


\title{
Children's narratives: a case study at an institution of early childhood education
}

\author{
Tizuko Morchida Kishimoto \\ Universidade de São Paulo \\ Maria Letícia Ribeiro dos Santos \\ Dorli Ribeiro Basílio \\ Escola Municipal de Educação Infantil Benedicto Castrucci
}

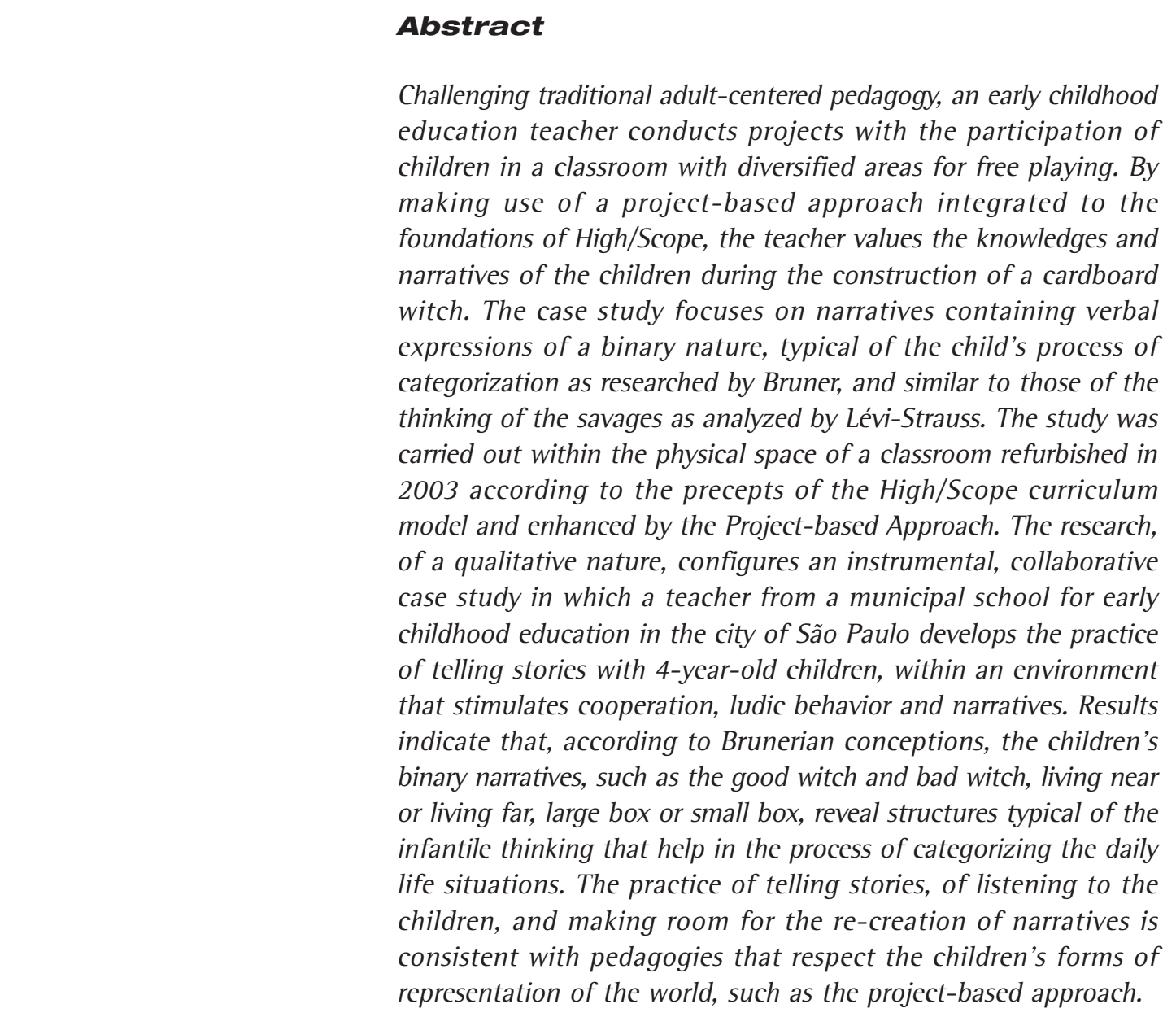

Contact:

Tizuko Morchida Kishimoto

Faculdade de Educação da USP

Av. da Universidade, 308/Depto EDM

05508-040 - São Paulo - SP

e-mail: tmkishim@usp.br

\section{Keywords}

Children's narratives - Project-based approach - Binary thinking Scaffolding. 


\section{Objetivos do estudo de caso}

As escolas municipais de Educação Infantil em São Paulo não têm especificidade. Caracterizam-se pelo modelo tradicional, adultocêntrico, de concepções e práticas que reproduzem formas de organização dos espaços e dos tempos pedagógicos, similares ao do Ensino Fundamental: salas com mesas e cadeiras, quadro negro que ocupa toda parede, alfabeto no topo, armários fechados, para um agrupamento massificado de 35 a 40 crianças de quatro a seis anos e um adulto, atividades fragmentadas, que focalizam conteúdos curriculares sem participação da criança, acrescido de um sistema perverso de três turnos diários (Kishimoto, 2001; Gomes, 2005).

Em uma dessas escolas, após um período de formação, uma professora enfrenta resistências, mas faz inovações, alterando sua prática. Nesse processo, suas crianças conduzem projetos, entre os quais o da construção de uma bruxa, com caixas de papelão, que estimula a expressão de narrativas infantis.

0 objetivo é investigar, com base na teoria de J. Bruner, as concepções subjacentes às inovações e às características das narrativas infantis que acompanham o projeto das bruxas no interior de um processo que integra a formação, a pesquisa e a inovação.

\section{Quadro teórico}

0 estudo focaliza uma profissional em formação dentro de um paradigma participativo, defendido por vários autores entre os quais Pascal, Bertram e Ramsden (1994) e Pascal e Bertram (apud Oliveira-Formosinho; Formosinho, 2001), em parceria com universidade, escola infantil, professores, crianças e suas famílias e que constrói uma pedagogia da infância que orienta suas práticas. A formação é um conceito dinâmico, que pressupõe o aperfeiçoamento profissional, pela reflexão sobre a prática pedagógica, como condição para que se alcancem níveis mais elevados de serviços educativos (Oliveira-Formosinho; Kishimoto, 2002).
Adota-se o conceito de profissionalização, proposto por Day (1999), Hargreaves (1994), Fullan e Hargreaves (2000), de professores reflexivos e proativos, que têm voz e saberes, opondo-se à tradição de excluí-los das decisões do cotidiano. Dewey $(1959 ; 1955)$ já mencionava, no início do século XX, a importância da reflexão, não como ato individual, mas cooperativo, como aprendizagem ampliada em contexto democrático. As culturas colaborativas (Hargreaves, 1994; Fullan; Hargreaves, 2000; Lima, 2002) favorecem aprendizagens de melhor qualidade, geram confiança profissional e capacidade dos professores de iniciarem e responderem às mudanças. Outro eixo para a profissionalização no campo da Educação Infantil é a compreensão das peculiaridades das pedagogias da transmissão e da participação para a construção de sua práxis.

Nas instituições infantis, a Pedagogia Tradicional enclausura a criança no espaço físico da sala, com mesas e cadeiras, armários fechados e a direção do adulto em todo o processo educativo. As Pedagogias de Participação, também conhecidas como construtivistas ou socioconstrutivistas, ancoram-se em ambientes educativos abertos, cooperativos, baseadas em concepções de criança e de educação nas quais as ações são partilhadas. Aprende-se em um mundo de interações com pessoas e objetos, em contextos sociais e culturais.

Entre as pedagogias da infância que estimulam a participação (Oliveira-Formosinho; Kishimoto; Pinazza, 2007), encontram-se duas modalidades divulgadas em nosso país e que são objeto deste estudo: High/Scope e Abordagem de Projetos.

0 High/Scope (Hohmann; Banet; Weikart, 1995; Hohmann; Weikart, 1997; Post; Hohmann, 2000), que utiliza concepções de Piaget e Smilanski, tem como pressupostos: a organização de experiências-chave, a aprendizagem pela ação, a interação adulto e criança, as áreas de aprendizagem, os registros; e o planejar, fazer e rever. A reorganização do espaço físico, em áreas de aprendizagem, facilita a ação protagonizada das crianças que desenvolvem experiências por elas iniciadas. Essa abordagem, desde os anos 90 
do século passado, começa a fazer parte das reflexões dos profissionais da Educação Infantil no Brasil.

Na Abordagem de Projetos, segundo Katz e Chard (1997), "a principal característica [...] é que ela é um esforço de pesquisa deliberadamente centrado em encontrar respostas para questões levantadas pelas crianças" (p. 1). As crianças se empenham em resolver problemas de seu interesse, com auxílio do professor. A Abordagem de Projetos tem bases teóricas sólidas em Dewey $(1924$; 1954; 1955), seguida por muitos outros, entre os quais Malaguzzi (2001), que propõe a tomada de decisões como um direito da criança e a expressão de projetos por meio de cem linguagens (Reggio Children, 1995; 1996). Embora a maioria dos estudos sobre projetos inclua esses teóricos, neste, utilizam-se concepções de Bruner, ainda pouco divulgadas, mas de grande relevância para a condução de projetos que incluam narrativas infantis.

As concepções brunerianas foram utilizadas para a compreensão das ações das crianças que, após ouvir histórias sobre bruxas, constroem narrativas com diferentes linguagens.

\section{Concepções de J. Bruner}

Jerome Seymour Bruner tem vasta produção teórica sobre aprendizagem e desenvolvimento infantil. Ele pesquisa como o bebê constrói seus saberes e elabora uma concepção de aprendizagem por descoberta, que depende da criança e do apoio do adulto; como a criança representa o mundo, expressa saberes; e como os contos de fadas contribuem para o desenvolvimento de mentes narrativas. Dessa forma, cria espaço para delinear pedagogias que favorecem a iniciativa da criança, o protagonismo, a aprendizagem e a expressão do conhecimento, pressupostos encontrados na Abordagem de Projetos. Por tais razões, o psicopedagogo, que atua na interface entre a psicologia e a educação (Cambi, 1999), é referência para a compreensão de práticas como a abordagem de projetos, relacionada com as narrativas infantis.
Na segunda metade do século XX, influenciado por Vygotsky, Leontiev e Bakhtin, Bruner estuda abordagens que tratam a linguagem como artefato cultural. Mais recentemente, preocupado com as formas específicas do pensamento infantil, em Actual minds, possible worlds, propõe a narrativa para dar sentido ao mundo e à experiência da criança e alinha-se aos estudiosos que relacionam os contos de fadas à cognição (Egan, 1991; 1995; Biddle; Good; Goodson, 2000).

Como uma forma de discurso, que descreve fatos em seqüência do passado, real ou imaginário (Bruner, 1996), a narrativa ocorre em linguagem articulada oral ou escrita, imagem fixa ou móvel, gesto, mito, lenda, fábula, conto, novela, epopéia, história, tragédia, drama, comédia, pantomima, pintura, vitral, cinema, histórias em quadrinhos, situações diversas e conversação (Barthes,1976).

A narrativa está presente na conversação, no contar e recontar histórias, na expressão gestual e plástica, na brincadeira e nas ações que resultam da integração das várias linguagens, dando sentido ao mundo e tornando essencial sua inclusão no cotidiano infantil.

Bruner $(1986$; 1996) valoriza as histórias infantis, do gênero conto de fadas, porque nelas se encontra um formato, uma estrutura prévia, de tipo binário, de situações opostas, típico do processo de categorização. A narrativa, como categorização, "exige discriminar diferentes coisas como equivalentes, agrupar objetos, eventos e povos em classes, em termos de membros de classe" (Bruner; Goodnow; Austin, 1956, p. 1). A categorização possibilita a aprendizagem, porque identifica objetos do mundo, reduz a complexidade do ambiente, mas requer motivos postos pela criança e estratégias para sua finalização. Para Bruner (1973), pensar é categorizar e resolver problemas. No processo de categorização, a mente humana utiliza um sistema binário, similar ao computacional (pertencer ou não à categoria), mas vai além da informação dada, utilizando inferências e indicações do ambiente. Cada indivíduo constrói um siste- 
ma de codificação, uma forma pessoal de agrupar ou relacionar informações sobre o mundo em constante reorganização.

Para Bruner (1986), a estrutura binária dos contos fantásticos auxilia a criança a construir suas narrativas. Povos selvagens descritos por Lévi-Strauss $(1976$; 1991) dispunham de estratégias similares em seus mitos. 0 pensamento selvagem não era fraco, intuitivo, concreto e sem abstração. Os totens dessas sociedades são classificações complexas, comparáveis aos sistemas de signos. A partir da oposição binária, o autor aponta propriedades gerais do pensamento mítico, no qual se encontram desde exemplos de aliança matrimonial até uma filosofia da sociedade e do espírito. As categorias empíricas binárias, como as de cru e cozido, fresco e podre, molhado e seco, oriundas da observação sensorial, do ponto de vista de uma cultura particular, levaram os povos a construírem noções abstratas, uma ciência do mundo concreto. Para Lévi-Strauss (1976; 1991), o pensamento selvagem é abstrato, dotado de sistemas classificatórios, baseado em percepções e descrições minuciosas, mas muito complexo, indicando uma lógica dentro de cada cultura. As classificações, como estruturas, auxiliam povos sem escrita a compreenderem seu mundo pela memória. Tais povos observam animais corredores, voadores e rastejadores, viajantes da terra, da água, diurnos e noturnos. 0 sistema binário, que prevalece nas narrativas, possibilita classificar um ser como voador ou não, noturno ou diurno, com descrições minuciosas, o que também se aplica às crianças, porque a mente infantil também usa tal sistema para a compreensão do mundo.

Situações binárias, como segurança e perigo, coragem e covardia, inteligência e estupidez, esperança e desesperança, bem e mal, são as principais tramas dos contos de fadas. No conto João e Maria, a criança se depara com a falta de segurança, o medo das florestas e a segurança do lar, binômio compreendido com facilidade, porque faz parte do cotidiano infantil.

A criança precisa de mediação, em situações familiares, para a compreensão dos conceitos. No caso de quente e frio, os conceitos intermediários, como aquecimento ou esfriamento, levam à percepção de suas nuances e facilitam a sua compreensão. Em conceitos físicos, é mais fácil perceber os mediadores. E em outros, como morte e vida, animal e humano, natureza e cultura? Para Egan (1995), duendes, seres fantásticos e mágicos, personagens típicos dos contos de fadas, são os mediadores da narrativa. Nas histórias infantis, os animais, descritos de forma antropomórfica, com comportamento meio humano e meio animal, possibilitam o uso do conhecimento disponível no mundo infantil, suas vivências para a compreensão do personagem, não por associação, mas por substituição metafórica, como faz Lewis Carroll nas Aventuras de Alice no País das Maravilhas.

Era uma vez um lobo mau que comeu a vovozinha ou uma princesa que foi salva pelo príncipe e... viveram felizes para sempre mostra uma seqüência: início, meio e fim, conhecida por crianças acostumadas a ouvir contos. 0 uso de estruturas lingüísticas (dêiticos) como então, depois, auxilia a seqüência dos eventos, o encadeamento de ações, os saberes de que a criança dispõe, assinalando o fio da história.

Bruner (1986; 1996), Egan (1991; 1995) e Sutton-Smith (1995), ao propor que as crianças, na condição de protagonistas, modifiquem a história, dialoguem com vários textos, incluindo situações não canônicas, provenientes de outras histórias ou de suas vivências, que tornam a narrativa diferente e relevante, intuem o papel das narrativas infantis como uma janela para o desenvolvimento do pensamento infantil.

Crianças de uma escola municipal de Educação Infantil da cidade de São Paulo recontam e modificam histórias, como a do lobo mau que tinha duas pernas (homem) e matava os animais (matança de animais do zoológico paulistano divulgada pela mídia) e que o lobo do bem vivia no zoológico e tinha quatro patas. Uma criança criou nova versão para Chapeuzinho Vermelho: escolheu o caminho errado na floresta. A inserção de fatos do cotidiano, em agrupamento multicultural de crianças brancas, negras e mulatas, aparece no 
reconto da história de Branca de Neve e os Sete Anões, no personagem Morena das Neves (Gomes, 2005). A estrutura binária: bom/mau, certo/errado, presente nos contos e nas situações vividas pelas crianças, facilita a elaboração e expressão de significados por sua ordenação em duas categorias: pertencer e não pertencer. A incorporação de personagens do cotidiano infantil é prática comum nas histórias criadas por crianças de quatro a cinco anos do Colégio D. Pedro V, de Braga, Portugal, que incluem a pesquisadora que as visitava na história Tiuko e a sementinha.

As narrativas infantis que alteram a canonicidade das histórias tornam as crianças protagonistas, construtoras de mundos reais e possíveis, relevantes e dignos de serem contados, ensejando a intertextualidade, a criação de textos que integram elementos de várias histórias infantis, o que pressupõe a mediação do adulto, que disponibiliza o acesso ao mundo da cultura adulta. Assim, as narrativas infantis são também ferramentas para desvendar o mundo encantado dos contos de fadas.

A preocupação de Bruner (1965) com os processos intuitivos e criativos da mente já aparece em On knowing: essays for the left hand, obra destinada à mão esquerda, vista como menos ordenada, racional e metódica que a mão direita. 0 ensaio reflete o esforço pela formulação de uma concepção integrada do ser humano, como cientista, humanista e artista (Anglin, 1973). Observando o lúdico na aquisição da linguagem, na comunicação entre adulto e criança, no seio de uma cultura, Bruner conclui que "as bases da educação são poéticas” (Apple apud Egan, 1991, p. 13) e que a criança vive como poeta. Assim, para desenvolver a compreensão poética, é necessário incluir a fantasia e construir teorias e práticas que a estimulem. Huizinga (1951) já chamava a atenção para a educação grega, que incorporava artes, poesia, música e lúdico. A tendência de excluir a fantasia, a narrativa e o jogo simbólico para valorizar a racionalidade é prática comum dos currículos infantis (Egan, 1991), como registram Kishimoto (2001) e Gomes (2005) em pesquisas nas escolas municipais de Educação Infantil na cidade de São Paulo.

Para Egan (1991), “o mítico é a primeira forma de compreensão de quase tudo que tem a ver com o pensamento humano" (p. 48). Há diferenças entre a narrativa infantil e a dos mitos, mas ambas se desenvolvem na forma de histórias. No mito, a narrativa é carregada de sagrado, enquanto a da criança é marcada pelo contato com o cotidiano e suas histórias. No mito e nas narrativas infantis, há elementos organizadores binários como medo/segurança, morte/vida.

Para Egan (1991), na cultura oral dos tempos homéricos, a aprendizagem se fazia em nível somático, para auxiliar a memorização. 0 jogador utilizava um instrumento, como o tambor, cuja percussão reforçava o ritmo da declamação. 0 público, convidado a viver o relato, não ficava passivo, mas recriava movimentos. 0 ritmo acústico, acompanhado pelo instrumento, apoiava-se nos movimentos rítmicos do corpo e da história, que levavam os participantes a criarem conexões. Dessa forma, o corpo todo se envolve na memorização. Perspectiva similar aparece em Siegler (1978), para quem a mente infantil se desenvolve pela memória, com uso de habilidades/competências do corpo.

Bruner vê a percepção como um processo indissociável da cognição e da personalidade. A maioria de seus estudos sobre percepção, publicados entre 1946 e 1958, fase do New Look (Kishimoto, 1976), indica que a memória se integra à cognição. Posteriormente, em Studies in cognitive growth, Bruner (1966) mostra como a criança vê seu mundo por formas integradas da ação (enativa), percepção (icônica) e linguagem (simbólica). Separar o movimento das percepções gráficas e da linguagem oral ou escrita é contrariar as formas de representação do mundo da criança, que são integradas, que resultam de atividades em contexto, que são ferramentas para expressão de significações.

A representação enativa (movimento do corpo), repetição de movimentos, é uma forma de 
memorização que, conforme Egan (1991), remete para as formas poéticas, diferentes da escritura. Nesse processo, cabe papel essencial às emoções que, segundo Bartlett (apud Egan, 1991), “são mais eficazes para manter e ajudar a recordar os acontecimentos” (p. 69). A relação entre memória e poesia é estreita na mitologia grega. Mnemosina é a deusa da memória e mãe das musas. Na tradição oral, a memória é uma força ativa e, especialmente na recuperação da informação, razão e memória se superpõem. Busca-se na memória a seqüência de fatos (razão) para a recuperação do evento. A forma narrativa, presente na rima, no ritmo, na métrica e na repetição de fórmulas, comuns nas culturas orais e nas brincadeiras infantis, revela a memorização como pensamento metafórico presente na mente infantil (Cassirer, 1974).

A questão que se coloca é como crianças de culturas letradas acessam recursos de uma cultura do passado até sua entrada no mundo da escrita.

Egan (2002) indica que "estudiosos da infância, como Opie (1959; 1969; 1985), Knapps (1976) e Sutton-Smith (1981)", mostram como, "pela rima de apelidos, enigmas, jogos e entesouramento do conhecimento popular e da linguagem da criança" (p. 88), a cultura oral perpassa séculos e cria as condições para o pensamento metafórico. 0 quadro de Pieter Bruegel (Áries; Margolin, 1982), Jogos Infantis, de 1560, contém de 86 a 90 brincadeiras tradicionais que, em sua grande maioria, perduram até hoje pela comunicação entre os brincantes (Bateson, 1985), a circulação e a apropriação das idéias, mesmo com as alterações do modo de vida dos tempos atuais. Nessas brincadeiras, prevalecem narrativas de grande riqueza, como as descritas em nosso país por Cascudo (1954; 1967; 1984a; 1984b), Kishimoto (1993), Fernandes (1979), Nogueira (2005) e outros e que continuam sendo reproduzidas e recriadas pelo universo infantil.

Como explicar a narrativa infantil como construção da criança que depende do adulto e da cultura?

Para McEwan e Egan (1995), o andaime (scaffolding) é a metáfora bruneriana para de- signar a construção da narrativa com auxílio do adulto. 0 andaime pode ser identificado na atividade de nomear, da criança de oito meses a um ano e seis meses, que brinca de ver livros ilustrados. A criança mostra interesse, toma iniciativa e aponta para a imagem. A mãe, ao verbalizar o nome do objeto apontado, cria o andaime ou a ZDP de Vygotsky. A mãe dispõe de um saber que a criança ainda não tem completamente. Para auxiliar nesse processo, usa diferentes formas de diálogo por andaimes (Ninio; Bruner, 1978). 0 diálogo, que surge no ato de nomear, aparece nas primeiras interações, quando a mãe responde seletiva e imitativamente aos gestos e vocalização da criança e esta à mãe. As primeiras formas de diálogo orientam-se para coisas, objetos que passam das mãos da mãe para a criança e desta para a mãe na forma de jogo. 0 jogo exibe característica de diálogo, que se desenrola com papéis, turnos de pegar, iniciar e responder. Bruner (1983b) observa que a criança tem consciência das intenções da mãe e já dispõe de um self transacional, com reciprocidade na ação. Por volta de seu primeiro ano de vida, já está apta a seguir a linha do olhar do outro para procurar um objeto que atrai a atenção de seu parceiro. Isso requer uma concepção sofisticada da mente, que implica intersubjetividade para perceber intenções do outro.

Desde o nascimento, a criança mostra intencionalidade, em ações de saber-fazer, relacionadas à alimentação, percepção ou atenção, manipulação do ambiente, locomoção e interação com membros da espécie. Segundo Bruner (1983a), "a organização de um saber-fazer precoce requer intenção, definição de um objetivo final e indicação mínima de meios” (p. 87), vale dizer, o grau de competência depende do ato voluntário, intencional, que desencadeia esquemas de ação na busca de objetivos como o da sucção. Na linha de Vygotsky (apud Bruner, 1987), Bartlett (1958), Bernstein (1967) e Lashley (1951), Bruner observa que o saber-fazer depende da intenção do sujeito, com pequenas séries de ações que se integram e se adaptam. 0 saberfazer é construído por meio de interações da 
criança, especialmente com a mãe, dependendo das formas de maternagem. Ao pesquisar o papel da intencionalidade nas primeiras ações do bebê, Bruner questiona educadores que de fora para dentro querem ensiná-lo, contrariando sua forma de aprender, que é por descoberta.

As idéias de descoberta e motivação são os pilares de sua teoria de aprendizagem divulgadas em The Process of Education (1960) e explicitadas em La Pédagogie par la Découverte (Shulman; Keislar, 1973). Os conteúdos culturalmente destinados à educação do homem não se descobrem, mas são transmitidos; a linguagem é uma invenção humana transmitida pela cultura. É pela reflexão sobre as próprias ações (self-loop), pelo ato intencional, motivado, que se constroem concepções com uso de informações que se transformam em aprendizagem por descoberta. 0 aprender só tem significado quando se constrói, o que implica descobrir (Bruner, 1973). Aprender, descobrir e construir fazem parte do mesmo processo.

Se a boa aprendizagem conduz o desenvolvimento (Bruner, 1996), como atingi-la antes deste?

Sozinha, a criança não o consegue, mas se o adulto coloca andaimes, uma forma de tutoramento, cria possibilidades para a aprendizagem e para a construção do mundo. Para Goodman (apud Bruner, 1986), não existe um mundo real independente da atividade mental e da linguagem simbólica. 0 que se chama de mundo é um produto de mentes humanas. Bruner (1986) descreve como a realidade é construída pela mente infantil nas narrativas, o que explica o título do seu livro: Actual minds, possible worlds. Como construtivista convicto, Bruner (1996) acredita que todo ser humano constrói-se e constrói o mundo pela ação e simbolização.

\section{Metodologia}

A investigação, de natureza qualitativa (Denzin; Lincoln, 1998a; 1988b; 2000), focaliza um estudo de caso, no qual a professora, em processo de formação, reorganiza sua prática e conduz, junto com as crianças, um pro- jeto sobre histórias infantis. Classifica-se como um caso instrumental (Stake, 1995; Gómez; Flores; Jiménez, 1999) ao fazer a leitura da abordagem de projetos, na perspectiva de Bruner, como relevante para a construção de narrativas. É também uma modalidade de investigação cooperativa, envolvendo a pesquisadora, a coordenadora e a professora. Os dados foram coletados por questionários, avaliações e entrevistas com a professora, imagens do cotidiano infantil, portfólios e registros da coordenadora. A análise dos dados foi efetuada à luz das concepções brunerianas definidas no quadro teórico. A fidedignidade dos dados foi garantida por meio da triangulação das fontes, como entrevistas, avaliação e portfólio da professora, registros diversos e imagens. 0 período da pesquisa: janeiro de 2003 a maio de 2006.

0 agrupamento, objeto do estudo, na Escola Municipal de Educação Infantil (EMEI) Benedicto Castrucci, na cidade de São Paulo, no período das 15 às 19 horas, tem 36 crianças de 4 anos. Maria Letícia atua na área há mais de 24 anos, com 10 anos de trabalho nessa escola e formação superior em Pedagogia. Já foi diretora de instituição infantil e dobra o período em outra unidade infantil pública, na cidade de Osasco-SP.

\section{Análise dos dados}

A nova prática de ouvir crianças, dar autonomia, criar áreas de escolha de brincadeiras resultou de concepções que a professora construiu no curso de formação em contexto, coordenado pelo Grupo de Pesquisa: Formação em Contexto, da Faculdade de Educação da Universidade de São Paulo, e que a levou a desconstruir a pedagogia tradicional (Santos, 2003a).

Ester Barocas, responsável pela formação, discutiu com as professoras dessa escola municipal, durante o primeiro semestre de 2003, diversas abordagens pedagógicas para infância, entre as quais o High/Scope e a Abordagem de Projetos, possibilitando à Maria Letícia compreender concepções que subsidiaram sua nova prática: papel mediador do adulto, autonomia da criança, 
aprendizagem colaborativa, organização do espaço físico e dos materiais e a relevância das brincadeiras, dos registros e do mundo de interações e das histórias infantis na expressão da criança. A formadora descreve o processo de inovação:

Letícia começou a socializar sua prática, trouxe um portfólio riquíssimo com atividades do projeto e produções das crianças, dei um retorno bem positivo, de como a sua mediação era de qualidade, acho que foi a primeira vez que senti esperança de melhoria, senti que 'valeu a pena', situei que o que ela estava fazendo era uma ampliação do que interessava às crianças, entrando adequadamente nos 'momentos mágicos' e realizando um tipo de projeto emergente. (Barocas, Relatório, 7/7/2003)

0 acompanhamento das novas práticas é registrado pela coordenadora pedagógica, uma entusiasta da proposta de reorganização do espaço físico, de inserção de brinquedos na sala, para uso independente das crianças: "Presenciei um verdadeiro parto do nosso projeto". A coordenadora descreve longamente como a Maria Letícia faz cama para as bonecas, delimita a área dos jogos, coloca tapete na área de construção e inúmeras brincadeiras de faz-de-conta, registrando a expressão por meio do brincar (Basílio, Relatório, 21/02/2003).

Gomes (2005), que fez pesquisa sobre narrativas infantis na mesma escola infantil, no período de 2003/2004, ressalta:

Maria Letícia desenvolvia uma prática muito interessante, oferecia autonomia às crianças, contava histórias, envolvia as crianças, mas não divulgava sua prática entre os professores com receio da cultura docente burocrática que prevalecia [...]. (Depoimento)

As pressões das culturas docente e institucional contrárias às práticas inovadoras contribuem para o silêncio da professora e retardam o início do estudo do caso que se deu apenas em 2005/2006.
Assim, parece que Maria Letícia ofereceu autonomia às crianças, acreditou nos seus saberes, evidenciou que é no mundo de relações que se expressam os conhecimentos e criou espaço para a agência no sentido bruneriano. A professora construiu uma imagem de criança e de educação infantil compativel com as inovações implementadas, como mostram seus depoimentos:

Criança é agente do processo de construção do conhecimento, dotada de potencialidade e capacidade de transformação da realidade. [...] acredito na prática voltada para a criança como um ser [...] capaz de construir, ampliar, transformar conhecimentos através das hipóteses que elabora, do confronto e das inter-relações que estabelece com o objeto de conhecimento e com outros indivíduos. (Santos, 2003, Entrevista)

Maria Letícia analisa sua práxis mostrando o impacto da inclusão de áreas opcionais como: construção, faz-de-conta, cozinha, livros e artes na sala de atividades, ampliando a ação protagonizada, a autonomia, o interesse e a atitude investigativa para a criança. As reflexões sobre as áreas opcionais e as pedagogias da infância, como o High/Scope (Hohmann; Weikart, 1997) e a Abordagem de Projetos (Malaguzzi, 2001; Reggio Children, 1995; 1996; Dewey, 1959; Katz; Chard, 1997), no curso de formação, foram essenciais para o entendimento da autonomia e do protagonismo infantil como pressuposto para a ação pedagógica, eixos condutores de projetos como o do dinossauro, dos bebês, dos passarinhos, da bruxa, entre outros (Santos, 2005).

As inovações da professora fazem parte do projeto político pedagógico da EMEl Benedicto Castrucci, divulgadas na Coordenadoria do Butantã e em dois números da Revista do Município de São Paulo, Diálogo em 2003. 0 texto de janeiro relata o início de parceria com a universidade e o de maio traz a nova proposta, informando que ela segue concepções socioconstrutivistas, na busca coletiva de soluções para aspectos da pedagogia como "espaço físico, tempo e relações interpessoais” (Diálo- 


Tabela 1: Auto-avaliação de Maria Letícia: prática anterior - sala tradicional, com mesas e
cadeiras e direção do adulto
\begin{tabular}{|l|c|c|c|c|c|l|}
\hline \multicolumn{1}{|c|}{ Categorias } & Nivel 1 & Nivel 2 & Nivel 3 & Nível 4 & Nivel 5 & \multicolumn{1}{c|}{ Justificativas } \\
\hline $\begin{array}{l}\text { Protagonismo } \\
\text { da criança }\end{array}$ & & & & & $\begin{array}{l}\text { Adoção de temas de interesse das } \\
\text { crianças. O Projeto era detalhado } \\
\text { apenas pelo adulto. Hipóteses } \\
\text { sobre a escrita das crianças } \\
\text { geravam, às vezes, o } \\
\text { protagonismo infantil. }\end{array}$ \\
\hline $\begin{array}{l}\text { Narrativas } \\
\text { infantis }\end{array}$ & & $X$ & & $\begin{array}{l}\text { Valorização da construção da } \\
\text { escrita pela criança gerava } \\
\text { narrativas infantis, em alguns } \\
\text { momentos, de grande } \\
\text { significação. }\end{array}$ \\
\hline $\begin{array}{l}\text { Suporte do } \\
\text { adulto } \\
\text { (andaime) }\end{array}$ & & & $X$ & & $\begin{array}{l}\text { Osuporte, exceto em alguns } \\
\text { casos, é oferecido de modo geral } \\
\text { para todas as crianças. }\end{array}$ \\
\hline
\end{tabular}

Tabela 2: Auto-avaliação da prática atual com as áreas de experiências e a condução de projetos

\begin{tabular}{|l|c|c|c|c|c|l|}
\hline \multicolumn{1}{|c|}{ Categorias } & Nivel 1 & Nivel 2 & Nivel 3 & Nivel 4 & Nivel 5 & \multicolumn{1}{|c|}{ Justificativas } \\
\hline $\begin{array}{l}\text { Protagonismo da } \\
\text { criança }\end{array}$ & & & & & & $\begin{array}{l}\text { Introdução das áreas de livre } \\
\text { escolha gera projetos } \\
\text { conduzidos pelas crianças. A } \\
\text { prática centrada na ação das } \\
\text { crianças respeita os seus } \\
\text { interesses, cria agência, } \\
\text { define o percurso do projeto e } \\
\text { estimula o protagonismo. }\end{array}$ \\
\hline $\begin{array}{l}\text { Narrativas } \\
\text { infantis }\end{array}$ & & & & $\times$ & $\times$ & $\begin{array}{l}\text { Áreas de exploração } \\
\text { revitalizam, no processo } \\
\text { interativo, a expressão de } \\
\text { narrativas. }\end{array}$ \\
\hline $\begin{array}{l}\text { Suporte do } \\
\text { adulto } \\
\text { (andaime) }\end{array}$ & & & & $\times$ & $\times$ & $\begin{array}{l}\text { Prática centrada no ouvir e } \\
\text { observar a criança estimula } \\
\text { suportes diferenciados. }\end{array}$ \\
\hline
\end{tabular}

go, 2003, p. 25). Uma das imagens divulgadas em maio traz a sala de atividade sem mesas e cadeiras, organizada com áreas para brincadeiras simbólicas. A mudança da pedagogia transmissiva para outra, que elimina mesas e cadeiras e introduz áreas como cozinha e quarto, construção, artes, linguagem, proporciona experiências no mundo imaginário e estimula as expressões infantis. 0 projeto político pedagógico denominado Pensando o currículo da Educação Infantil, publicado em maio de 2003 pela Revista Pedagógica do Município, divulga a experiência realizada na sala do $1^{\circ}$ estágio, compartilhada por três professoras, uma das quais a colaboradora deste estudo. Entre os eixos principais da proposta, encontram-se: a valorização do brincar, a construção da autonomia da criança, o trabalho colaborativo com a universidade, o self-service, a parceria família/comunidade e o investimento na formação profissional.

\section{Auto-avaliação da prática}

Para compreender as razões que levaram a professora, foco deste estudo, às inovações, foi sugerido que se analisasse a prática anteri- or e a atual, com uso de uma escala com 5 pontos, criada por Ferre Leavers (1994) e revista por Pascal e Bertram (1999), destinada à observação do envolvimento da criança e do empenho do adulto. Nesse caso, três questões foram objeto de atenção: o protagonismo da criança, as narrativas infantis e o suporte do adulto (andaime). Para cada pontuação da escala, exigiu-se uma justificativa para sua atribuição:

1. não há presença da categoria

2. há muito pouco e de baixa qualidade

3. há de vez em quando com boa qualidade 4. há de forma quase contínua e com boa qualidade

5. há de forma contínua e de boa qualidade

Antes da inovação, Maria Letícia contava história para toda turma e não achava relevante o recontar história. Dispunha de sala com mesas e cadeiras, armários fechados e desenvolvia uma prática, ainda tradicional, dando suporte à classe toda, sem atender às expectativas de cada criança. Às vezes, preocupada com as hipóteses de escrita das crianças, criava um pequeno espa- 
ço para alguma criança com protagonismo expressar suas narrativas. Por tais razões, atribui o nível $3 \mathrm{em}$ todas as categorias.

Após a reorganização da sala, com a inclusão de áreas opcionais de brincadeira, Maria Letícia percebe o quanto as histórias mobilizam as crianças para outras ações que as transformam em protagonistas de seus projetos com a participação da professora. Essa autonomia estimula o mundo de interações e amplia as narrativas infantis. 0 suporte do adulto (andaime) se multiplica pela atenção individualizada, favorecendo as interações e a construção de narrativas. As professoras the diziam: "A gente nunca te vê na sala!" Ela estava na biblioteca pesquisando com um grupo, procurando material para dar suporte a outro ou interagindo, sentada no chão, ouvindo e criando andaimes para algumas crianças (Santos, 2006). No processo socioconstrutivista, a figura do professor é secundária, um suporte, assim como os materiais e os espaços, tendo primazia a voz da criança, as ações compartilhadas, suas narrativas no mundo de interações, a Pedagogia Visível. Centrada nas propostas das crianças, não era o centro das atenções, o que a levou a atribuir níveis entre 4 e 5 na fase de inovações.

\section{Construindo e analisando as narrativas}

No quiosque localizado no pátio externo, Maria Letícia desenvolve práticas de contar histórias com o livro Bruxa, bruxa, venha à minha festa, de Arden Druce e Pat Lodlow:

Começo a trazê-los a participar da história [...]. Realizamos uma leitura compartilhada. A trajetória é emocionante. Gosto quando percebo os olhos brilhando [...], a participação é extraordinária. No parque havia tantas bruxas... dragões... fantasmas... e eu acabei entrando no jogo. Em 27/03/2003, apresento uma nova história, Quem tem medo de bruxa? - Fanny Joly e Jean Noel Rochit. A participação das crianças é muito significativa. Ao estabelecer um paralelo entre as histórias, pedem-me para pegar o livro Bruxa, bruxa, venha à minha festa e, com o apoio da ilustração, contam a história na íntegra. É impressionante o fascínio que a história provoca, o caráter lúdico é extremamente prazeroso. (Santos, 2003a, p. 23)

Ao abandonar práticas espontaneístas e adotar a abordagem de projetos, observando e registrando os interesses da criança, a professora percebe o interesse pelas histórias da bruxa e cria espaços para o imaginário em que bruxas, dragões, fantasmas aparecem nas brincadeiras de perseguição e multiplicam as narrativas infantis. Há continuidade das ações planejadas intencionalmente pela professora junto com as crianças: do lúdico à mediação do adulto, de momentos de ação educativa dirigida a outros livres, em que cabe à criança tomar as rédeas da ação, que são reveladas pelas novas concepções adotadas e divulgadas em sua entrevista: de criança como "agente do processo de construção do conhecimento", dotada de "capacidade de transformação da realidade; de educação infantil como" momento de construção, interação e ampliação do conhecimento, tendo o lúdico um papel preponderante nesse processo (Santos, 2003, Questionário).

0 interesse pelas histórias traz o desejo das crianças de construção de uma bruxa, com caixas de leite. Configurado o tema do projeto, a professora oferece um andaime, ao disponibilizar o livro Artesanato para crianças com mil e uma coisas, para auxiliar nessa empreitada, para que se possam utilizar diferentes formas de expressão, o que Bruner, Goodnow e Austin (1956) denominam formas de representação do mundo. 0 artesanato fornece recursos para representação, por meio gráficos ou formas tridimensionais, que são modalidades de linguagem. No cotidiano infantil, infelizmente, as Artes não são vistas como recursos para a expressão do conhecimento adquirido pela criança, mas práticas rotineiras de desenhar, construir algum protótipo definido pelo adulto.

Os portfólios e as fotos contêm inúmeros exemplos de formas integradas de representação 
do mundo: enativa (teatro, gestos e movimento), icônica (desenhos e construções ) e simbólica (palavras e números), evidenciando sua contribuição para tornar a criança ativa e protagonista.

$\mathrm{Na}$ área da construção, criada após a adoção da proposta do High/Scope, peças, como Lego, caixas de sapato e de camisa estimulam ações de empilhar e construir, aguçam a observação e exploração dos materiais e o saber-fazer, como comparar a altura e a forma das caixas. A experiência prévia subsidia a comparação das dimensões das caixas e as relações com a altura dos pés da bruxa, confirmando que a exploração e a manipulação livre de materiais favorecem a solução de problemas (Bruner, 1976). A presença constante da coordenadora Dorli é outro saber construído pelas crianças para resolver seus problemas.

No processo de construção, a criança utiliza saberes já adquiridos, observa, compara e encontra a solução:

Um menino observa e compara as caixas. Pergunto o que havia. Ele disse: 'Essas não dá pra usar'. Por quê? - 'Por causa que a bruxa vai ficar com um pé alto e o outro baixo'.

0 que vocês precisam fazer? "Ir na Dorli e pedir mais caixas'.

Trouxeram outras caixas e ele espontaneamente começou a sobrepô-las. Pergunto: 0 que você está fazendo? - 'Veja esse lado, tá sobrando'. E assim processa o seu raciocínio até encontrar duas caixas semelhantes para os braços, duas para as pernas e duas para a cabeça. Quando questionados sobre o corpo, resolvem utilizar uma caixa de leite que estava disponível e visível na sala. (Santos, 2003a, p. 24)

A aprendizagem criativa ou por descoberta se processa quando a criança descreve seu raciocínio para a professora, explicando a inadequação das caixas para a construção do corpo e das pernas da bruxa.

A contextualização das atividades leva à emergência do letramento, como no episódio da destruição da perna da bruxa pelas crianças de outros agrupamentos infantis. 0 bilhete escrito pelas crianças revela o problema de uma sala compartilhada por três agrupamentos infantis, em três turnos diários.

Alguns dias após, a bruxa estava caída, a perna havia despregado. Reuni o grupo e resolveram escrever um bilhete/aviso para deixarmos junto à bruxa:

\section{A PERNA DA BRUXA DE CAIXA CAIU. CUIDA DA BRUXA, NÃO DEIXA NINGUÉM TOCAR NELA. \\ AS CRIANÇAS DA LETÍCIA AGRADECEM TAMBÉM.}

(Santos, 2003a, p. 25)

0 projeto prossegue com o desejo das crianças de produzir o vestido da bruxa, evidenciando a continuidade das ações como indício de interesse e esforço para a busca do objetivo (Dewey, 1959). A professora fornece andaimes para a confecção da roupa da bruxa, sugerindo alfinetes para prender o tecido. As crianças assumem, de forma autônoma, as ações de vestir a bruxa: Natália e Ana Lúcia põem o tecido e fazem a roupa sem cortar, prendem com alfinete para a roupa não ficar pequena e aparecer o corpo. Mayara dá a idéia de colocar a peruca. Natália pega a peruca no armário. As crianças pesquisam livros para fazer o chapéu, por sugestão de Mayara. Quando decidem fazê-lo com papelão preto, uma das crianças lembra que podiam utilizar uma cartolina que havia pintado com tinta preta (Santos, 2003a).

0 projeto da bruxa beneficiou-se de saberes já adquiridos pelas crianças com a implantação das áreas de aprendizagem do High/Scope, possibilitando a coordenação de um saber-fazer com outros mais complexos e a repetição de ações com vista ao aperfeiçoamento como pintar papéis, prender com alfinete, colocar peruca, observar dimensões de caixas, empilhar, colar, comparar a altura de caixas, entre outras. 0 protagonismo da criança, a experiência com a 
diversidade de materiais e o suporte do adulto contribuem para a aprendizagem pela descoberta e a solução de problemas (Bruner, 1996). Na avaliação da professora,

[...] é importante a participação [das crianças] no planejamento, na realização, o que supõe que façam, atuem, realizem e compreendam o que estão executando, responsabilizando-se pelo que fazem e tenham critérios para avaliar e modificar o que for necessário. (Santos, 2003b, p. 6)

As crianças solucionam o problema da dimensão correta das caixas para a construção das pernas e dos braços da bruxa porque já experimentaram empilhar caixas, na rotina do High/Scope, ao brincar livremente na área de construção. Bastou desvelar o novo contexto para que a solução aparecesse. Esse é o sentido da aprendizagem por descoberta, uma ação de des(cobrir). Não é um ato de criação vazio de saberes, mas baseado em uma experiência prática, em um saber-fazer adquirido, fruto de coordenação de outros saberes, estimulado por um contexto que problematiza e estimula a busca de soluções.

\section{Categorização e pensamento binário}

A professora indaga se a bruxa teria um nome.

Uma criança diz: Bruxa Keka, aceito por várias crianças. Fica por alguns minutos observando a bruxa e exclama: 'Olha o sorriso dela!!! Ela é boazinha!!!'

Outra não aceita e retruca: 'Não! A Bruxa Keka faz maldade e também põe o dedo no nariz e põe sujeira na boca’. (Santos, 2003a, p. 28)

A dicotomia boa e má aparece na narrativa das crianças. A representação icônica (sorriso) classifica a bruxa de boa e a experiência pessoal de sujeira, de má. Pôr o dedo no nariz e sujeira na boca são atributos de maldade, concepções construídas na cultura. Aprender e pensar, para Bruner (1996), estão fortemente imbuídos de formas culturais.

Houve sugestão de vários nomes: Bruxinha Feliz (10 votos), Bruxinha Alegre (3 votos) e Bruxa Boa (9 votos). Quando a coordenadora percebe que, com mais um voto, a Bruxa Boa empata, pergunta se pode votar.

'Não, acabou!!! Tá bom de risco na lousa'. Outra diz: 'Dorli, não'. Pergunto: Por quê?

‘-Dorli é grande'. (Santos, 2003a, p. 29)

A oposição pequeno e grande surge mais uma vez para eliminar Dorli do processo de votação do nome da bruxa. A construção da identidade da bruxa passou pela categorização do bom e do mau, mas a afeição pelo personagem fez prevalecer o bom. Todos os nomes com mais votos possuem o perfil positivo: feliz, boa e alegre.

Uma criança, ao perceber que sobra um voto, diz: 'Quem ganhou foi Bruxinha Feliz porque tem mais votos'. (Santos, 2003a, p. 29)

Pela observação dos traços na lousa, surge a emergência do letramento matemático que ocorre concomitante à aquisição da linguagem escrita, na denominação da bruxa e produção de bilhetes para outros agrupamentos não a danificarem. As múltiplas linguagens ou formas de representação do mundo (Bruner, 1996) evidenciam a abrangência do pensamento infantil, que integra, na narrativa, formas enativas (ações motoras de brincar de bruxa), icônicas (desenhos e construções) e simbólicas (significados, símbolos), que representam a emergência da linguagem escrita e da matemática.

Crianças e pais destacam o prazer na construção da bruxa: pintar, desenhar, fazer escultura e até na organização da festa para a bruxa, evidenciando a prática de ouvir e dar voz às crianças e envolver os pais nas atividades cotidianas (Santos, 2003b). 
A história coletiva A bruxinha feliz possibilita a análise de inúmeras concepções brunerianas:

Era uma vez uma bruxinha muito alegre que gostava de crianças. Ela vivia sorrindo.

Um dia a Bruxa Malvada prendeu a bruxinha na grade. Ela ficou muito triste. Aí... depois... chorou... chorou... chorou... e dormiu.

Ela teve um pesadelo e acordou muito chateada.

Depois ela viu a Bruxa Malvada e o cavaleiro que tava escondido.

O cavaleiro pôs a Bruxa Malvada no caldeirão e ferveu.

A Bruxa Malvada foi para bem longe... lá no norte.

Aí veio o príncipe e casou com a Bruxinha Feliz, que abraçou todas as crianças e ficaram felizes para sempre. (Santos, 2003a, p. 29)

A história construída revela na intertextualidade (Bruner, 1986; 1990; 1996) a integração de contos com bruxas e príncipes. A bruxa assume o lugar da princesa e se casa com o príncipe. 0 bem e o mal são retratados nas bruxas malvada e alegre.

0 fio da história é típico do gênero contos de fadas: era uma vez e ficaram felizes para sempre. "Aí... depois..." são dêiticos que indicam aspectos, como tempo e lugar, dando seqüência ao conto, e repetições, como "chorou... chorou... chorou... e dormiu", muito utilizadas por contos infantis e, com prazer, pelas crianças em outras narrativas, como a do "cão que cheirou... cheirou e cheirou...” (Gomes, 2005, p. 112). Ocorrem desvios da canonicidade, quando as crianças usam expressões que lhes chamam atenção para recriar novas situações, transformando a cultura do adulto em cultura infantil pela aprendizagem por descoberta.

A situação imaginária, de algo distante da atividade cotidiana, surge quando a bruxa, fervida no caldeirão, não morre, mas vai para longe. Durante a produção do texto, uma criança diz: A Bruxa Malvada "foi para bem longe”. Outra criança complementa: "lá no norte", com sotaque bem carregado, característico de sua origem nordestina. Outra criança tenta imitá-la, com ar de deboche. A primeira, muito segura, intensifica a sua pronúncia, um confronto que mostra as variantes da língua e a aceitação de contextos diversos.

Considerando que $58 \%$ das famílias das crianças têm origem nordestina (diagnóstico efetuado pela escola em 2003), é compreensível que as narrativas, resultado da expressão livre, não sejam descarnadas, porém matizadas pelos valores e pelas características do caldo cultural em que as crianças estão imersas. A professora evidencia sua compreensão do ser humano (Bruner, 1996; Vygotsky, 1988) percebendo a complexidade do pensamento infantil que revela as características da cultura.

\section{À guisa de conclusão}

0 estudo de caso focaliza uma prática de construção de uma pedagogia da infância com uso de concepções do High/Scope e da Abordagem de Projetos por uma professora que valoriza as histórias infantis.

0 contar e recontar histórias em um ambiente que acolhe a criança e lhe dá voz é essencial para o desenvolvimento do pensamento infantil, de natureza categorial e binária. As narrativas infantis auxiliam a categorização de situações imaginárias como a bruxa boa e má ou o personagem que mora perto ou longe.

0 caso analisado evidencia, à luz das concepções brunerianas, como as ações das crianças, de natureza enativa, icônica e simbólica, se integram como diferentes formas de perceber o mundo pelo movimento, pelo grafismo ou pelos objetos tridimensionais, pela linguagem oral, escrita ou matemática, dando suporte para o pensamento categorial, binário, típico dos contos de fadas, das narrativas infantis e das conversações diárias das crianças.

No entender de Bruner, pedagogias que estimulam narrativas infantis garantem a integração de formas de representação do mundo pela criança, a intertextualidade, a mudança da 
canonicidade pela inserção da experiência infantil nas histórias recriadas, propiciando aprendizagens por descoberta, solução de problemas e desenvolvimento de mentes narrativas. A abordagem de projetos incorpora as concepções dessas pedagogias ao ouvir a criança, ampliar seu conhecimento, dar espaço para seu protagonismo, potencializar a expressão da criança e estimular o pensamento categorial, abstrato, que requer classificações.

0 estudo aponta o papel da formação em contexto na profissionalização docente que, conjugada à investigação, cria oportunidade para implementar, de forma consciente, mudanças nas práticas com vistas a uma educação de melhor qualidade.

No âmbito das políticas públicas, cabe registrar culturas docentes e institucionais autoritárias, que impedem inovações e gestões burocráticas que pouco compartilham questões pedagógicas e padronizam ambientes, criando equivocos, como a concepção de que a educação da criança requer igualdade de condições e não eqüidade.

\section{Referências bibliográficas}

BARTHES, R. et al. Análise estrutural da narrativa: pesquisas semiológicas. Petrópolis: Vozes, 1976.

BARTLETT, F. C. Thinking. New York: Basic Books, 1958.

BAROCAS, E. Relatório. São Paulo, $1^{\circ}$ semestre de 2003.

BASÍLIO, D. R. Relatório. São Paulo, $1^{\circ}$ semestre de 2003.

BATESON, G. Pasos hacia una ecologia de la mente: una aproximación revolucionaria a la autocomprensión del hombre. Argentina: Lohlé-Lumen, 1985.

BERNSTEIN, N. A. The coordination and regulation of movement. London: Pergamon Press, 1967.

BIDDLE, B. J.; GOOD, T. L.; GO0DSON, I. F. La ensenãnza y los profesores I: la profesión de enseñar. Buenos Aires: Paidós, 2000 BRUNER, J. S. A cultura da educação. Tradução de Marcos A. G. Domingues. São Paulo: Artmed, 2001.

Atos de significação. Tradução de Sandra Costa. Revisão Rogério de Castro Oliveira. São Paulo: Artmed, 1998. 1973.

Beyond the information given: selected, edited and introduced by Jeremy M. Anglin. London: George Allen \& Unwin, Child's talk: learning to use language. New York: W.W. Norton S., 1983b.

0 processo da educação. Tradução de Lólio Lourenço de Oliveira. São Paulo: Melhoramentos, 1969.

Le developement de l'enfant: savoir faire, savoir dire. Tradução de Michel Deleau. Paris: PUF, 1983a.

On knowing: essays for the left hand. Cambridge: Harvard University Press; New York: Atheneum, 1965.

Prologue to the English Edition. In: ROBERT, W.; CARTON, A. S. (Eds.). The collected works of L. S. Vygotsky, v. 1.

Problems of General Psychology including the Volume Thinking and Speech. New York: Plenum Press, 1987.

Realidade mental, mundos possíveis. Tradução de Marcos A. G. Domingues. São Paulo: Artmed, 1997.

BRUNER, J. B; GOODNOW, J. J.; AUSTIN, G. A. A study of thinking. New York: John Wiley \& Sons, 1956. 
BRUNER, J. S.; HASTE, H. (Eds.). Making sense: the child's construction of the world. London: Methuen, 1987.

BRUNER, J. S.; JOLLY, A.; SYLVA, K. (Eds.). Play: its role in development and evolution. New York: Penguin Books, 1976.

BRUNER, J. S.; OLVER, R.; GREENFIELD P. Studies in cognitive growth. Nova York: Wiley, 1966.

CASCUDO, L. da C. Contos populares do Brasil. Rio de Janeiro: J. Olympio, 1954.

Folclore no Brasil: pesquisas e notas. Rio de Janeiro: Fundo de Cultura, 1967.

Literatura oral no Brasil. São Paulo: Edusp, 1984a.

Vaqueiros e cantadores. São Paulo: Edusp, 1984b.

CAMBI, F. História da Pedagogia. Tradução de Álvaro Lorencini. São Paulo: UNESP, 1999.

CASSIRER, E. Language and myth. Tradução de Susanne K. Langer. New York: Imprenta, 1974.

DAY, C. Desenvolvimento profissional de professores: os desafios da aprendizagem permanente. Porto: Porto Editora, 1999.

DENZIN, N. K I.; LINCOLN, Y. S. (Eds.). Collecting and interpreting qualitative materials. London: Sage Publications, 2000. . Handbook of qualitative research. London: Sage Publications, 1998a.

The landscape of qualitative research: theories and issues. London: Sage Publications, 1998b.

DEWEY, J. Como pensamos. Tradução de Haydée de Camargo Campos. São Paulo: Companhia Editora Nacional, 1959.

School of tomorrow. 15 ed. Nova York: E.P. Dutton, 1924.

. Vida e educação. Tradução e estudo preliminar de Anísio S. Teixeira. São Paulo: Melhoramentos, 1954.

Democracy and education: an introduction to philosophy of education. Nova York: Macmillan, 1955.

EGAN, K. La compreensión de la realidad en la educación infantil y primaria. Madrid: Morata, 1991.

. A mente educada: os males da educação e a ineficiência educacional das escolas. Rio de Janeiro: Bertrand Brasil, 2002.

. Narrative in teaching: learning, and research. In: HUNTER, M.; EGAN, K. (Eds.). Narrative in teaching: learning, and research. New York: Teachers College Press, 1995, p. 211-225.

FERNANDES, F. Folclore e mudança social na cidade de São Paulo. Petrópolis: Vozes, 1979.

FULLAN, M.; HARGREAVES, A. A escola como organização aprendente: buscando uma educação de qualidade. Porto Alegre: Artes Médicas, 2000.

GÓMES, G.; FLORES, J.; JIMÉNEZ, E. Metodologia de la investigación cualitativa. Málaga: Aljibe, 1999.

GOMES, H. S. Narrativas infantis: contribuição para a autoria da criança. 2005. Dissertação (Mestrado)- Faculdade de Educação da Universidade de São Paulo, São Paulo, 2005.

HARGREAVES, A. Changing teachers, changing times: teachers work and culture in the postmodern age. London: Teachers College Press, 1994.

HOHMANN, M.; WEIKART, D. Educar a criança. Lisboa: Fundação Calouste Gulbenkian, 1997.

HOHMANN, M.; BANET, B.; WEIKART, D. P. A criança em acção. Lisboa: Fundação Calouste Gulbenkian, 1995.

HUIZINGA, J. Homo ludens: essai sur la fonction sociale du jeu. Paris: Gallimard, 1951. 
KATZ, L.; CHARD, S. A abordagem de projeto na educação de infância. Lisboa: Fundação Calouste Gulbenkian. 1997.

KISHIMOTO, T. M. Brinquedos e materiais pedagógicos nas escolas infantis. Educação e Pesquisa, 2001. v. 27, n. 2, p. 229-246. Jogos infantis. Petrópolis: Thompson Learning, 1993.

J. Bruner: contribuições para o desenvolvimento do currículo. 1976. Dissertação (Mestrado)- Faculdade de Educação da Universidade de São Paulo, São Paulo, 1976.

LASHLEY, K. S. The problem of serial order in behavior. In: JEFFRESS, L. A. (Ed.). Cerebral mechanism in behavior: The Hixon Symposium, Wiley, New Horm, p. 112-146, 1951.

LEAVERS, F. (Ed.). The leuven involvement scale for young children LIS-YC. Manual. Belgium: Centre for Experiential Education, 1994

LÉVI-STRAUSS, C. 0 pensamento selvagem. Tradução de Maria Celeste da Costa e Souza e Almir de Oliveira Aguiar. 2 ed. São Paulo: Companhia Editora Nacional, 1976.

0 cru e 0 cozido. São Paulo: Brasiliense, 1991.

LIMA, J. de As culturas colaborativas nas escolas: estruturas, processos e conteúdos. Porto: Porto Editora, 2002.

MALAGUZZI, L. La educación infantil em Reggio Emília. Traducción de Alfredo Hoyuelos. Espana: Octaedro, 2001.

McEWAN, H.; EGAN, K. (Eds.). Narrative in teaching, learning and research. New York; London: Teachers College; Columbia University, 1995.

NINIO, A.; BRUNER, J. The achievement and antecedents of labeling. Journal of Child Language. v.5, p. 1-15, 1978.

NOGUEIRA, M. E. de A. C. Jogos, brinquedos e brincadeiras no Brasil colonial. 2005. Tese (Doutoramento)- Faculdade de Educação da Universidade de São Paulo, São Paulo, 2005.

OLIVEIRA-FORMOSINHO, J.; FORMOSINHO, J. Associação criança: um contexto de formação em contexto. Braga: Livraria Minho, 2001. .; KISHIMOTO, T. M. Formação em contexto: uma estratégia de integração. São Paulo: Thompson e Learning, 2002. .; KISHIMOTO, T. M.; PINAZZA, M. A. Pedagogia(s) da infância. Porto Alegre: Artmed, 2007. (Coleção Dialogando com o passado. Construindo o futuro)

PASCAL, C.; BERTRAM, T. Desenvolvendo a qualidade em parcerias: nove estudos de caso. Porto: Porto Editora, 1999.

POST, J.; HOHMANN, M. Educação de bebés em infantários: cuidados e primeiras aprendizagens. Lisboa: Fundação Calouste Gulbenkian, 2003.

STAKE, R. S. Investigación com estudio de casos. Madrid: Morata, 1995.

SIEGLER, R. S. Children's thinking: what develops? New York: L. Erlbaum, 1978.

SHULMAN, L. S.; KEISLAR, E. R. (Dir.). La pédagogie par la découverte. Tradução de René Dutour. Paris: ESF, 1973.

SUTTON-SMITH, B. Radicalizing childhood: the multivocal mind. In: MCEWAN, H.; EGAN, K. (Eds.). Narrative in teaching, learning, and research. New York; London: Teachers College; Columbia University, 1995. p. 69-90.

REGGIO CHILDREN. In viaggio coi diritti delle bambine e dei bambini. Itália, 1995.

Catálogo della mostra I Cento Linguaggi dei Bambini. Itália, 1996.

Revista Pedagógica: Diálogo. n. 1, janeiro de 2003, ano 1. 
. n. 2, maio de 2003, ano 1

VYGOTSKY, L. A formação social da mente. São Paulo: Martins Fontes, 1988.

Recebido em 11.10.06

Aprovado em 05.03.07

Tizuko Morchida Kishimoto é docente e pesquisadora da Faculdade de Educação da Universidade de São Paulo e coordenadora do Grupo de Pesquisa Contextos Integrados de Educação Infantil.

Maria Letícia Ribeiro dos Santos e Dorli Ribeiro Basílio são professoras na Escola Municipal de Educação Infantil Benedicto Castrucci. 